\title{
RUSKIN DIGITAL: UMA DISCUSSÃO SOBRE A NATUREZA DO ORNAMENTO NA AROUITETURA CONTEMPORÂNEA ${ }^{1}$
}

\author{
Diogo Ribeiro Carvalho
}

\section{Resumo}

DOI: 10.5752/P.2316-1752.2017v24n35p134

Desde 1990 uma condição ornamental tem sido instalada na arquitetura contemporânea. O presente artigo pretende apresentar a teorização que Lars Spuybroek faz do ornamento contemporâneo a partir de John Ruskin e discutir alguns projetos à luz de conceitos como textura, padrão, variação e mutabilidade. Se o retorno do ornamento é visível, é necessário o entendimento de sua natureza, de seus modos de operação e de seus contextos de aparição. Para tanto, o artigo realiza uma discussão da literatura mais recente sobre o tema.

Palavras-chave: Ornamento contemporâneo. John Ruskin. Textura. Padrão.

\footnotetext{
1. Este artigo toma por base investigação no doutoramento de Diogo Ribeiro Carvalho, no Programa de Pós-graduação em Arquitetura e Urbanismo (NPGAU) da Universidade Federal de Minas Gerais (UFMG), sob orientação do prof. Dr. Stéphane Huchet.

2. Arquiteto e Urbanista pela UFMG, mestre e doutor em Arquitetura e Urbanismo pela UFMG (NP-GAU). Professor do Departamento de Arquitetura da PUC Minas. Contato: diogo.pucminas@gmail.com.
} 
DIGITAL RUSKIN: A DISCUSSION OF THE NATURE OFTHE ORNAMENT IN CONTEMPORARY ARCHITECTURE

\section{Abstract}

Since 1990 an ornamental condition has been installed in contemporary architecture. This article aims to present the theory that Lars Spuybroek builds on contemporary ornament based on John Ruskin and discuss some projects in the light of concepts such as texture, pattern, variation and changeability. If the return of ornament is visible, then it is necessary to understand its nature, its operation modes and its contexts of appearance. Therefore, the article makes a discussion of more recent literature on the topic.

Keywords: Nature. Ornament. Art Nouveau. Morphogenesis. Emergence.
RUSKIN DIGITAL: UNA DISCUSIÓN SOBRE LA NATURALEZA DE LA ORNAMENTACIÓN EN LA ARQUITECTURA CONTEMPORÁNEA

\section{Resumen}

Desde 1990, una condición ornamental se ha instalado en la arquitectura contemporánea. Este artículo tiene como objetivo presentar la teoría de la ornamentación que hace Lars Spuybroek de John Ruskin y discutir algunos proyectos a la luz de conceptos tales como la textura, patrón, la variación y la mutabilidad. Si el retorno de la ornamentación ya visible, es necesaria la comprensión de su naturale$\mathrm{za}$, de sus modos de funcionamiento y de sus contextos de apariencia. Por lo tanto, el artículo hace una discusión de la más reciente literatura sobre el tema.

Palabras-claves: La naturaleza. Adornos. Art Nouveau. Morfogénesis. Emergencia. 


\section{Introdução}

A questão aqui não depende dos variados níveis de relacionamento ou autonomia entre ornamento e material em diferentes momentos históricos e diferentes práticas arquitetônicas. Ela depende, contudo, na observação de que finalmente o ornamento emerge como categoria pelo reconhecimento da forma como simbólica. ${ }^{3}$

O reconhecimento da condição ornamental na arquitetura contemporânea, pressuposto deste trabalho, exige a explicação dos seus modos de operação e das circunstâncias que a conformaram. A hipótese convencional que é compartilhada pelos principais arquitetos, historiadores e teóricos que atualmente têm trabalhado na historiografia e na teorização do ornamento contemporâneo ${ }^{4}$ - Greg Lynn (1993; 2002; 2004), Bernard Cache (1995; 2000), Neil Leach (2004), Robert Levit (2008), Farshid Moussavi e Michael Kubo (2008), Phillip Beesley e Sarah Bonnemaison (2008), Antonie Picon (2010; 2013), Alina Payne (2010; 2012; 2016),

3. LEVIT, Robert. Contemporary Ornament: The Return of the Symbolic Repressed. Harvard Design Magazine, Spring/Summer 2008, n. 28. 2008. p.3.

4. O fundamento do ornamento arquitetural e sua história menos recente também têm interessado arquitetos e historiadores como Kent Bloomer, David Morgan, Oleg Grabar, Alina Payne, dentre outros. Da bibliografia encontrada, apenas Phillip Beesly e Sarah Bonnemaison, organizadores do livro On Growth and Form: Organic Architecture and Beyond, de 2008, mostram uma intenção de cobrir a história e o discurso da arquitetura orgânica para discutir os novos interesses da arquitetura nas formas e nos sistemas complexos da natureza. 
Lars Spuybroek (2011), Marjan Colletti (2010; 2013) e Vittoria di Palma (2016), - é que o ornamento recente se inicia e se finda com a linha pós-moderna historicista e se observa seu retorno, mas em forma bem distinta, a partir da década de 1990. A historiadora italiana Vittoria di Palma (In PAYNE, 2016) fornece duas condições que possibilitaram e impulsionaram esse interesse: (1) a emergência de softwares e novas ferramentas de fabricação digitais, que permitem manipulação de formas complexas - da topologia aos fractais; no entanto, conforme argumenta a autora, a facilidade tecnológica por si só não justificaria a reinserção do ornamento na arquitetura. $\mathrm{O}$ impulso de realizar algo novo geralmente é o que dá suporte para a criação de tecnologias que permitam essa realização, e não o contrário. Pressupõe-se,

assim, (2) o surgimento de um desejo, um ímpeto, de ornamentar. No entanto, a conjuntura que despertou esse desejo permanece desarticulada e obscura.

Um equívoco que os teóricos do ornamento contemporâneo têm cometido é a consideração de que esse interesse se configura como um retorno e não como um ápice resultante de uma progressão histórica de circunstâncias na cultura marginal ${ }^{5}$ arquitetônica que favoreceram e cultivaram práticas ornamentais. A aparição do ornamento pós-moder-

5. O termo "marginal" está sendo utilizado em oposição à historiografia central que dominou a primeira metade do século XX, que apresenta o modernismo funcionalista como soberano e sem rivais. 
no não ocorreu sem precedentes históricos e, da mesma maneira, o ornamento contemporâneo não se conforma por geração espontânea.

A história oficial do ornamento na arquitetura contemporânea começa e termina nos discursos e na prática pós-moderna historicista, desde as investigações semióticas de Venturi e Graves aos racionalistas italianos e os contextualistas. Outras práticas que permearam as décadas de 1970 até 1990, do regionalismo crítico ao desconstrutivismo, utilizaram uma série de terminologias para identificar, categorizar e explicar suas formas, como a tectônica, o detalhe, a junção - no caso dos regionalistas críticos - e a dobra, o fragmento, o blob - no caso dos desconstrutivistas e dos que se configuram como arquitetos experimentais. Talvez pelo fato dos pós-modernos historicistas terem construído um discurso fundado na questão do significado e do simbolismo das formas e dos elementos arquitetônicos, isto é, a partir da gramática do ornamento e de elementos ornamentais, e terem sofrido duras críticas pela sua banalização, pela excessiva espetacularização e pela associação à mercantilização do espaço, as demais vertentes pós-modernistas se preocuparam em negar qualquer tipo de relação com a categoria ornamento para se legitimarem. Ainda assim, o ornamento agora é parte integral da cultura arquitetônica digital. 
Este artigo pretende elucidar um dos discursos arquitetônicos que tiveram influência na formação do "desejo" de ornamentar, bem como apresentar e discutir os conceitos operadores que caracterizam a condição ornamental da arquitetura contemporânea.

\section{A natureza do ornamento}

A abordagem mais consistente em termos teóricos e propositivos sobre o ornamento contemporâneo é a do holandês Lars Spuybroek ${ }^{6}$ (1959-), a partir dos livros The Sympathy of Things: Ruskin and the Ecology of Design e Textile Tectonics, ambos publicados em 2011. Spuybroek não só está atento e imerso na cultura digital, mas oferece uma visão fresca de conceitos-chave de teóricos do ornamento do século XIX e início do XX, em especial Ruskin, Semper, Morris, Owen Jones e Worringer. Em Sympathy of Things, o autor, a partir de sua empatia teórica com John Ruskin, formula uma hipótese sobre a "natureza digital do gótico" e interpreta e esclarece os principais operadores conceituais e práticos para conceber o ornamento. Spuybroek dedica um capítulo - The Matter of Ornament, "A matéria do ornamento" - aos fundamentos do ornamento de superfície. Para inaugurar essa discussão, o autor recupera a analogia

6. Spuybroek é fundador do escritório NOX (Rotterdam) com interesse nas relações entre arte e arquitetura. Desde 2006 atua como professor integral no Georgia Institute of Technology, Atlanta. 
que Ruskin faz entre a superfície da terra (o que chama de Earth-veil) e da parede (wall-veil). Há um caráter dinâmico nas forças geológicas necessárias para a formação da massa terrestre (interna) e na consequente conformação da superfície natural (externa). A configuração é ambígua, uma vez que é variada e imperfeita (relevo) e relativamente estável em sua superestrutura - porque é lenta pelo ímpeto interno (forças formativas) -, mas, ao mesmo tempo, está em constante mudança pela ação de suas próprias forças e elementos (externas, erosivas). Ruskin, pelo conceito de Earth-Veil, construído no quinto volume de Modern Painters (1860), evidencia a sabedoria da natureza e argumenta pela necessidade de reciprocidade entre o homem e o natural. Na verdade, ele diz sobre fazer parte, de se imbricar: "Vesti-la e com ela permanecer" - To dress it and to keep $i t^{7}$. Assim começa o texto de Ruskin, com uma citação do Genesis:

A terra nas suas profundezas deve permanecer morta e gelada, incapaz exceto de lenta mudança cristalina; mas na sua superfície, com a qual os seres humanos lidam e a reconhecem, ela atende suas necessidades através de um véu de um ser estranho intermediário: um que respira, mas não tem voz; que se move, mas sem poder sair de seu lugar determinado; passa sem consciência pela vida, para a morte sem amargura; veste a beleza da juventude, sem a sua paixão; e declina

7. RUSKIN, John. Selections From the Works of John Ruskin. Cambridge, Massachusetts: The Riverside Press, 2012. Kindle Edition. p.26. 
pela fraqueza da idade, sem seu arrependimento. ${ }^{8}$

A configuração dessa superfície é traduzida abstratamente por Ruskin de duas maneiras: o contorno variado das montanhas, das folhas, dos rios, é transformado em linha de força, expressão de sua configuração (a forma no tempo sua lógica de formação, movimento); o Earth-veil é o manto que recobre a massa da terra, cuja natureza é dobrada, isto é, é textural: "A textura da montanha - o wall-veil - não é apenas drapeada, mas também incrustada, coberta por seu próprio material, em um auto-drapeamento, um auto-adornamento"9. Gilles Deleuze diz que "a maneira pela qual uma matéria se dobra é que constitui sua textura: ela define-se menos pelas suas partes heterogêneas e realmente distintas do que pela maneira pela qual essas partes tornam-se inseparáveis em virtude de dobras particulares" 10 .

8. Idem.

9. SPUYBROEK, Lars. The Sympathy of Things: Ruskin and the Ecology of Design. Rotterdam: V2_Publishing, 2011. p.80.

10. DELEUZE, Gilles. A Dobra: Leibniz e o Barroco. Campinas: Papirus, 1991. p.69. Não será por acaso que o filósofo francês é particularmente relevante para a discussão contemporânea sobre ornamento. Desde os desconstrutivistas sua filosofia tem sido apropriada das mais variadas formas. Para nós, os textos mais relevantes serão A lógica da sensação, de 1981; A dobra, de 1988, e o capítulo O Liso e o Estriado de Mil Platôs, escrito com Guattari, de 1980, em que Deleuze relaciona o espaço liso - o espaço háptico de visão-de-curta-distância - e a geometria fractal. Benoit Mandelbrot, em 1983, escreve The Fractal Geometry of Nature e explica uma das principais lógicas formais generativas presentes na natureza. O fractal para Deleuze é a possibilidade de desdobra infinita da dobra. A geometria fractal se configurou com um dos principais operadores do que hoje está conhecida como "Arquitetura Biomimética", um dos desdobramentos recentes da arquitetura orgânica paramétrica e ornamental. 


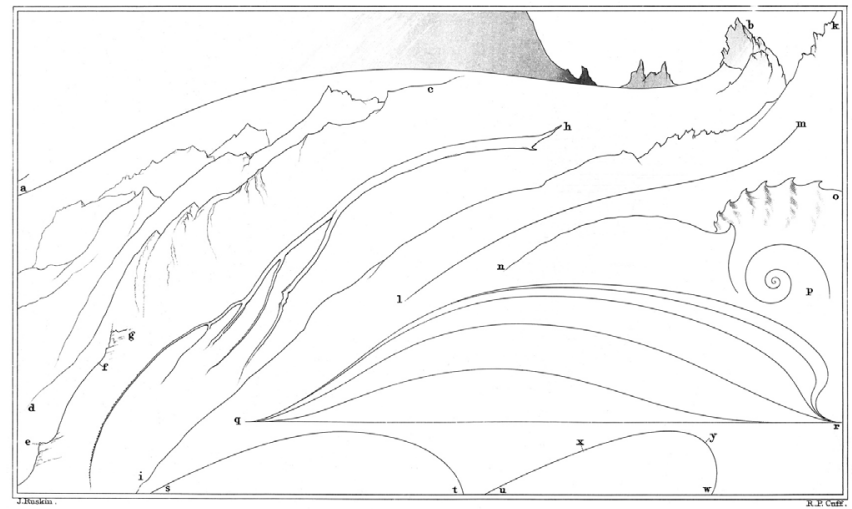

Figura 01 | Abstract Lines, usado por Ruskin em Pedras de Veneza (1851) para sugerir a abstração depreendida da natureza como um sistema do ornamento.

Fonte: http://www.victorianweb.org/ 
Ornamento de superfície é aquele que se manifesta na pele, no envelope, na membrana do edifício. Ele pode estar achatado ou disposto em camadas, mas geralmente é incrustado nessa pele exterior. Mais que uma analogia à tatuagem, é como as escamas de um réptil ou os dermatoglifos (marcas) da nossa pele. Ele é irremovível, fazendo o ornamento e a superfície serem uma entidade só.

A textura é um dos fundamentos da geração de superfícies, como reconhecido na proposição de Semper ${ }^{11}$ sobre a origem têxtil para a arquitetura e, consequentemente, para o ornamento. Não há nada sem textura. A textura é transdimensional: em nível microscópico ou macroscópico, ela se manifesta performaticamente, guia a formação da forma. Spuybroek ${ }^{12}$ combina os discursos de Owen Jones - de A gramática do ornamento de 1856 - e os de Gottfried Semper - Os quatro elementos da arquitetura de 1851 para fundamentar uma teoria do ornamento orientada pela matéria. A textura é uma configuração que se dá quando um número suficiente de linhas ou fibras estruturantes se agrupa para gerar uma superfície. Textura, texere, tecer. O entrelaçamento de linhas, a sua aglutinação, ou a junção desses dois processos gera superfícies. O primeiro pro-

11. Cf. SEMPER, Gottfried. The Four Elements of Architecture and other writings. Cambridge, UK: Cambridge University Press, 2010. 314p. Tradução de Harry F. Mallgrave e Wolfgang Herrmann.

12. Cf. SPUYBROEK, op cit. p.81-102. 
cesso tem configuração de esqueleto, de estrutura, como nos cristais de gelo; o segundo é como uma pele, algo que recobre uma estrutura, um drapeado, como mofo em um pedaço de madeira; o terceiro é mais sofisticado, pois envolve as forças internas que formam o primeiro processo e as externas do segundo: estrutura e pele se transformam juntas em superfície. Nesse caso, a superfície só se forma por essa interdependência, como o Earth-Veil (a superfície da terra), a asa de um morcego ou a copa de uma árvore. Spuybroek vê esse terceiro processo, proposto por Ruskin ${ }^{13}$, como uma nova teoria da ornamentação.

(...) a transformação de estrutura em textura é uma de refinamento, um recurso de escala, como ir de colunas nervuradas à traceira nervurada. A palavra "véu" é particularmente bem escolhida por Ruskin. Ornamento é uma demonstração de delicadeza, isto é, a superfície não é simplesmente feita de elementos ultrafinos e refinados, mas os elementos configuram, e, mesmo delicados como são, eles poderiam até suportar carga, porque eles configuram colaborativamente. ${ }^{14}$

Um importante exemplo do efeito textural na arquitetura digital é o edifício da loja Selfridges, em Birmingham, projetado em 2003 pelo escritório Future Systems, formado

13. Fusão do gótico nórdico (de linha, entrelaçamento) com o sulista (de superfície, incrustação). Cf. A Natureza do Gótico, em Pedras de Veneza. Sobre a relação entre linha, superfície e expressividade, Cf. A lâmpada do poder, em As sete lâmpadas da arquitetura. 14. Cf. SPUYBROEK, op cit. p.81. 
pelo arquiteto tcheco Jan Kaplický (1937-2009) e pela arquiteta inglesa Amanda Levete (1955-). O principal atributo do projeto é a superfície de concreto de curvatura dupla variável, que envolve todo o volume, revestida com calotas de alumínio anodizado. A enorme massa amorfa e sinuosa é ressaltada pela textura criada e de longe lembra a malha metálica de uma armadura medieval, destacando-se na paisagem. A posição de cada um dos 15.000 discos afixados na casca de concreto foi determinada parametricamente pela geometrização da superfície a partir do tamanho da unidade básica circular (cerca de 1 metro de diâmetro) e da distância entre cada unidade (cerca de 10 centímetros). Esses dois parâmetros foram fundamentais para a escala da textura ficar adequada para aquela situação urbana. Se a escala fosse muito grande, o efeito seria grosseiro; se fosse muito pequena, daria a impressão de uma superfície metálica homogênea - sendo assim, seria preferível o uso de chapas. Entre os discos e o concreto há um revestimento plástico azul que protege a superfície rígida da umidade e serve de fundo para destacar a malha metálica. Os efeitos cromáticos são interessantes, pois o material captura a luminosidade do dia e o contraste entre luz e sombra, gerado pelo espaçamento entre os discos e seu leve distanciamento da superfície, ressalta a dinamicidade topológica. 


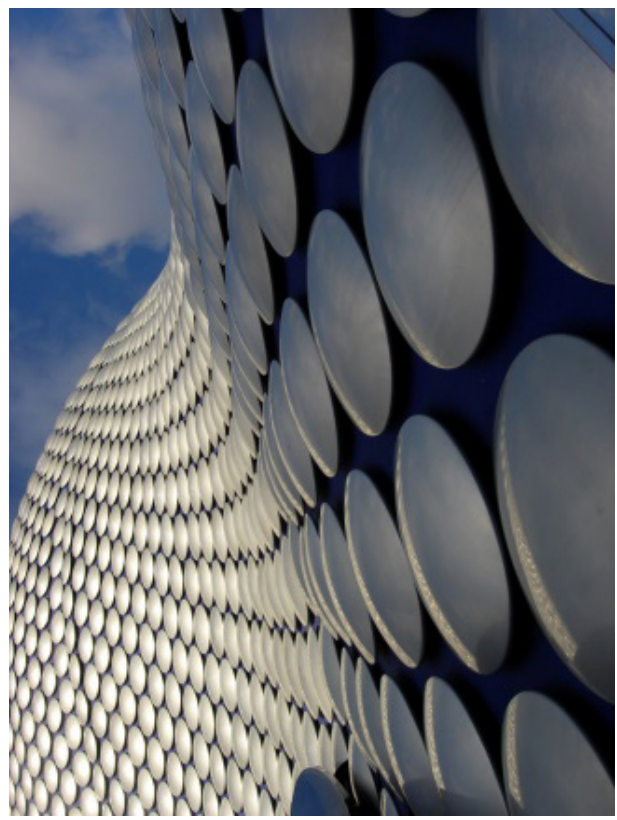

Figura 02 | Detalhe dos discos de revestimento, Selfridges (1999-2003). Fonte: Wikipedia Commons. 


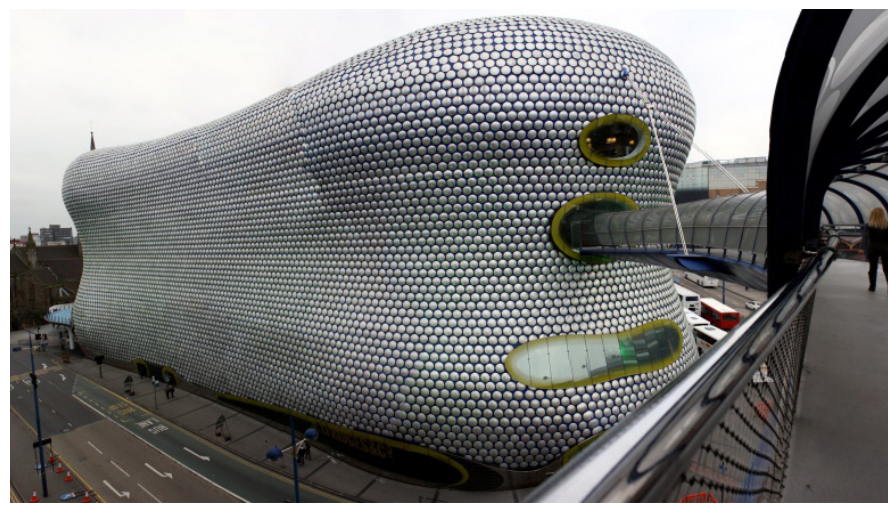

Figura 03 | O ameboide Selfridges (1999-2003). Fonte: Wikipedia Commons. 
Selfridges é o único edifício ameboide que Farshid Moussavi (2008) inclui na sua classificação em The Function of ornament. Esse tipo de experimento topológico será chamado de "BLOB" - Binary Large Object, termo cunhado por Greg Lynn ${ }^{15}$ (1964-) - cujo controle numérico para a construção industrializada será facilitada por meios digitais. Tanto Moussavi ${ }^{16}$ quanto Picon ${ }^{17}$ entendem que esse tipo de tratamento de superfície, pela dobra e pela textura, está nas origens do ornamento contemporâneo.

Contudo, a associação da prática ornamental contemporânea, exclusivamente às práticas digitais, é um equívoco. Para efeito de elucidação, pode-se pontuar: o arquiteto húngaro Imre Makovecz (1935-2011) projeta em 1979 um pequeno edifício que dá acesso ao teleférico da estação de ski de Dobogókö. Trata-se de uma forma orgânica cujo volume é todo revestido por réguas de madeira dispostas em angulações diferentes e sobrepostas como as penas

15. Greg Lynn é arquiteto americano pioneiro no campo do digital. Antes de abrir seu escritório FORM em 1994, estudou e trabalhou com Peter Eisenman, considerado seu mentor. Cf. Folds, Bodies and Blobs: Collected Essays, 1998. Para uma discussão inicial sobre a relação entre dobra, Deleuze e a teoria das catástrofes de René Thom, ver Architectural Curvilinearity: The Folded, The Pliant and the Supple, publicado originalmente em Architectural Design, mar-abr 1993.

16. Cf. MOUSSAVI, Farshid (ed.); KUBO, Michael (ed.). The function of ornament. Barcelona: Actar, 2008. s/p.

17. Cf. PICON, Antoine. Digital Culture in Architecture: an introduction for the design professions. Basel: Birkhauser, 2010. 224p. e PICON, A. Ornament: The politics of Architecture and Subjectivity. Chichester: John Wiley \& Sons, 2013. 168p. 
de uma ave. O efeito é uma textura dinâmica que de fato lembra um ser orgânico. Essa mesma estratégia já foi usada em 1961, por Herb Greene ${ }^{18}$ (1929-) na Prairie Chicken House, em Oklahoma. Nesse caso, até o interior é textural pela totalidade das superfícies serem revestidas de shingles de madeira. As peças pequenas de madeira são ideais para cobrir superfícies curvas. O efeito textural foi utilizado por Peter Zumthor (1943-) no revestimento de shingles da capela de Saint Benedict (1985-1988) e revestimento de quartzito filetado nas superfícies exteriores e interiores do bloco perfurado das Termas de Vals (1996). O projeto de Enric Miralles (1955-2000) e Carme Pinós (1954-), para o Cemitério de Igualada, (1984-1994) também é fundado nesses princípios e evidencia um trabalho compositivo altamente sofisticado: a textura dos sinuosos muros de gabião faz a transição do natural para o construído; as paredes de concreto ora rústicas ora lisas; o solo de brita e tábuas de madeira rústicas encrustadas; ali tudo desperta um sentido háptico, uma consciência do corpo e incita um alargamento da sensibilidade, inclusive por se tratar do espaço que realiza o ritual da passagem da vida para a morte.

18. Greene é vinculado à vertente da arquitetura orgânica. Foi aluno de Bruce Goff e trabalhou com John Lautner. 


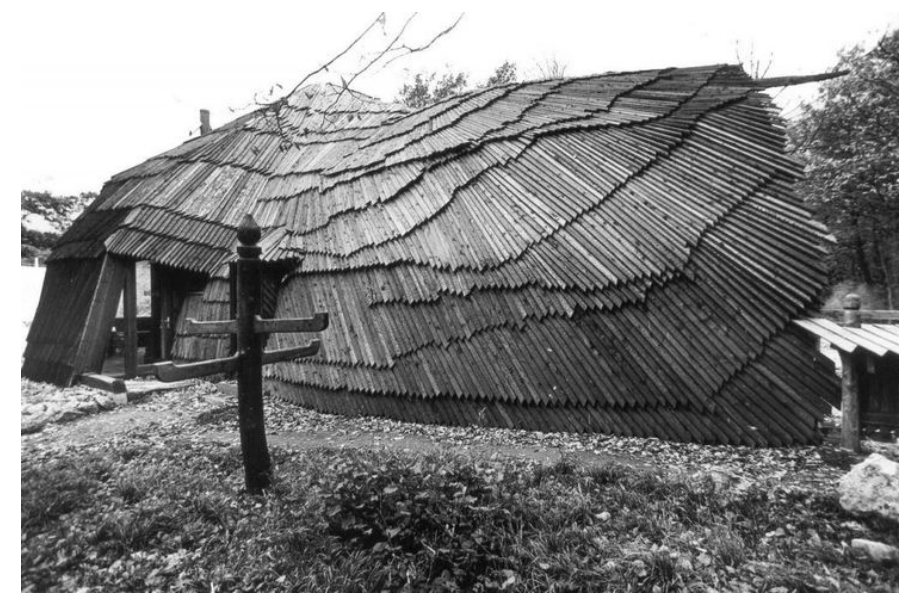

Figura 04 | Abrigo do teleférico, Dobogókölmre (1979), Makovecz. Fonte: Wikipedia Commons. 


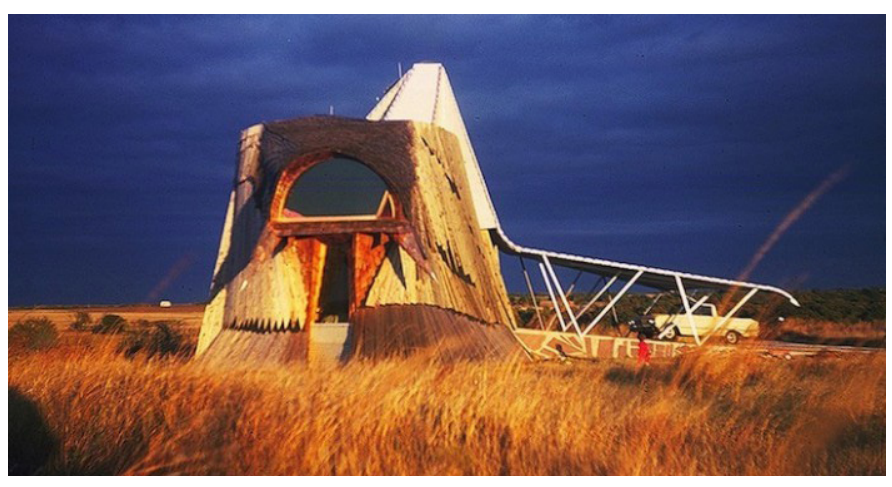




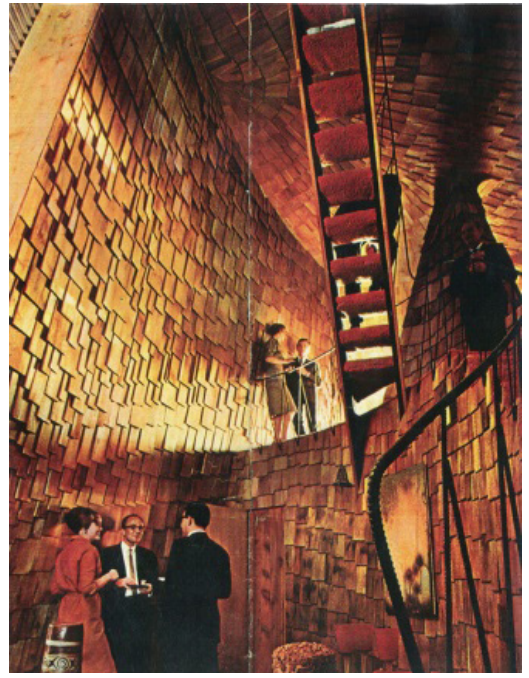

Figura 06 | Interior de shingle da Prairie Chicken House (1961), Herb Greene. Fonte: www.herbgreene.org 


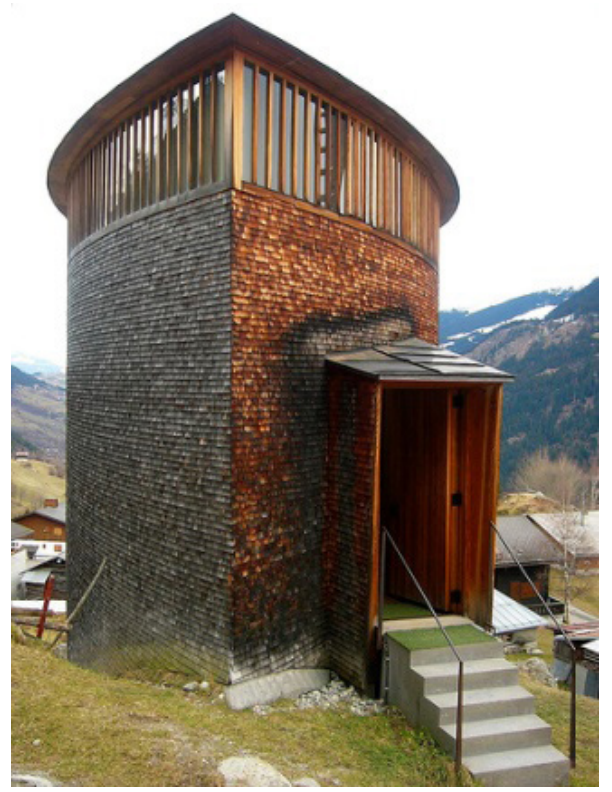




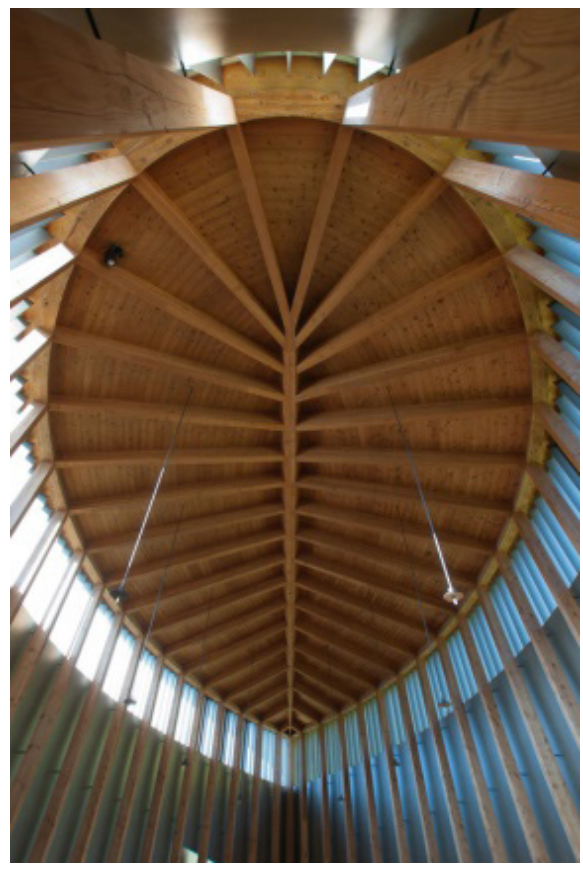

Figura 08 | Estrutura no interior da capela Saint Benedict (1985-1988), Zumthor. Fonte: Felipe Camus. www.archdaily.com. 


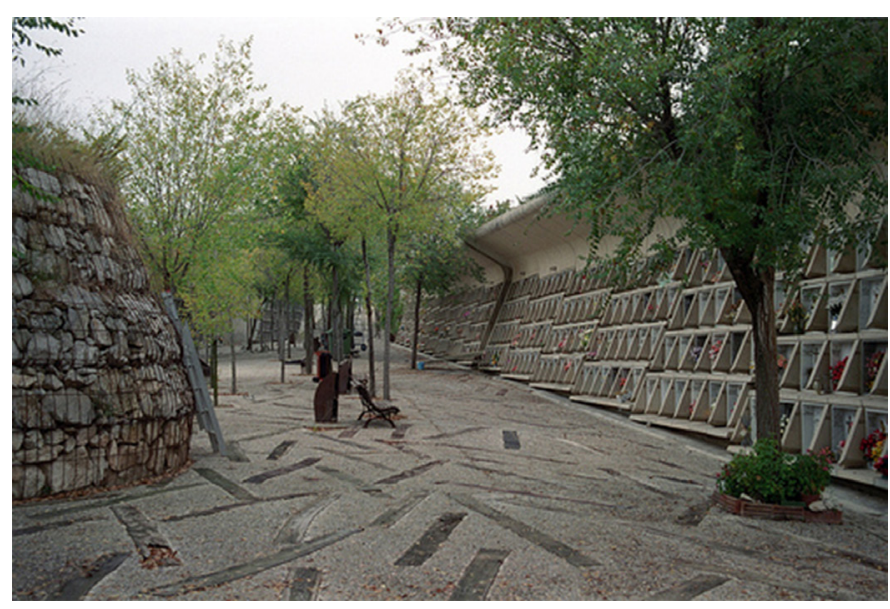




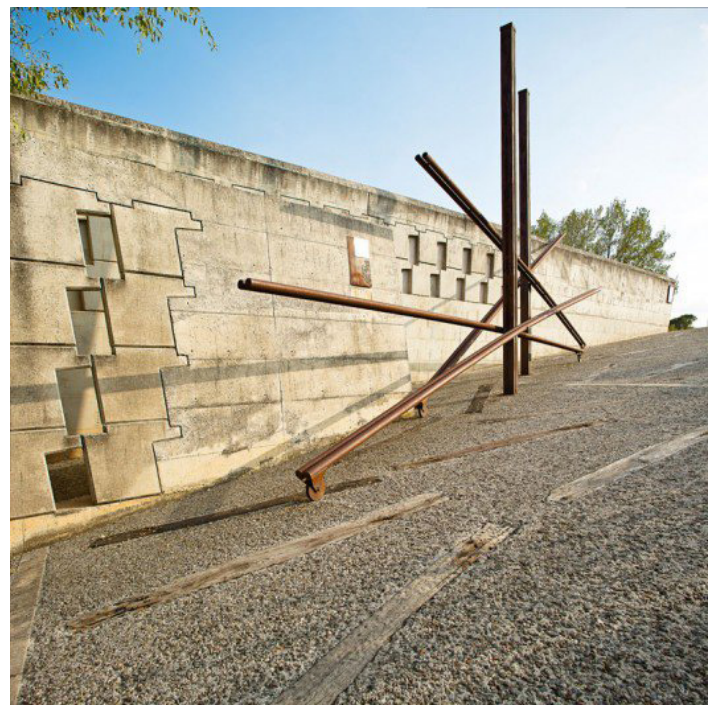

Figura 10 | Cemitério de Igualada, (1984-1994), Miralles/Pinós. Fonte: Wikipedia Commons 
A expressividade da textura deve-se ao modo como consegue capturar luz e gerar sombra. A natureza da matéria, os modos de sua configuração e de sua transformação provê a textura de profundidade, não de espaço, mas de superfície - "espessura magra"19. Quando se observa a recorrência de uma lógica na configuração de texturas naturais, por exemplo, o que se descobre é um padrão. Do mesmo modo, quando, em um ímpeto criativo, se intenta a expressão textural por meio de uma lógica recorrente de formação de linhas em figuras e sua transformação em superfície, cria-se um padrão. O padrão (pattern) é uma das encarnações do ornamento e é um princípio formativo. Na natureza é possível encontrar padrões, isto é, princípios formativos, em tudo; na lógica de crescimento das árvores, de formação de folhas e flores. No entanto, árvores de uma mesma espécie nunca são idênticas, mas seguem uma mesma lógica de desenvolvimento de sua forma; assim como não há um ser humano igual ao outro, não há uma só folha em uma árvore com a mesma disposição de veios, mas possuem sempre o mesmo princípio. Assim, o padrão é constituído simultaneamente de variação e de uniformidade. Owen Jones ${ }^{20}$ enuncia que a variação é explicada pela consistência de comportamento, e não pela igualdade

19. DELEUZE, Gilles. A Dobra: Leibniz e o Barroco. Campinas: Papirus, 2011. 6 ${ }^{\text {a }}$ Ed. Tradução de Luiz Orlandi. p.70.

20. JONES, Owen. A gramática do ornamento: ilustrado com exemplos de diversos estilos de ornamento. São Paulo: Editora SENAC, 2010. p.478. 
das formas: "Porque a beleza nasce naturalmente da lei do crescimento de cada planta" 21 . A variedade de formas só é possível pela repetição da lógica de sua formação. Todas as configurações naturais, cujas matérias foram arranjadas a partir de forças internas e externas que as diferenciam, são padrões. Assim, como declara Spuybroek: "Nada escapa à decoração"22.

\section{O ornamento digital}

A prática ornamental na cultura arquitetônica digital possui um início um tanto improvável. Uma das primeiras publicações em que o ornamento foi assumido ${ }^{23}$ como característica determinante de certa prática arquitetônica foi o periódico alemão $A R C H+129 / 130$, uma edição especial de dezembro de 1995 para os trabalhos de Jacques Herzog e Pierre de Meuron, subintitulada: Minimalismus und Ornament. Minimalismo e ornamento. Essa combinação é inusitada e quase contraditória, se não fosse de fato o modo mais adequado de categorizar a prática desse escritório atualmente. A produção de Herzog \& de Meuron tem oscilado entre materialidades simples - lajes superpostas

\footnotetext{
21. O reconhecimento da perfeição da lei natural e sua associação à beleza é fundamento comum em qualquer discurso naturalista, organicista ou ecológico.

22. SPUYBROEK, op cit. p.96.

23. De modo geral, muitas das práticas ornamentais contemporâneas ainda não possuem um discurso em torno do ornamental e preferem associar sua prática à tecnologia, à filosofia ou à natureza.
} 
revestidas lateralmente por vidro - e complexas - superfícies inteiras sob a influência de padrões ornamentais que envolvem o edifício. Três dos seus primeiros experimentos com ornamento são: o Edifício de produção e depósito da fábrica Ricola-Europe SA, em Mulhouse-Brunstatt, França (projeto, 1992 e construção, 1993); a Biblioteca da Escola Técnica Eberswalde, Eberswalde, Alemanha (projeto, 19941996 e construção, 1997-1999) e a sede do vinhedo Dominus Winery, em Napa Valley, California (projeto, 1995 e construção, 1996-1998).

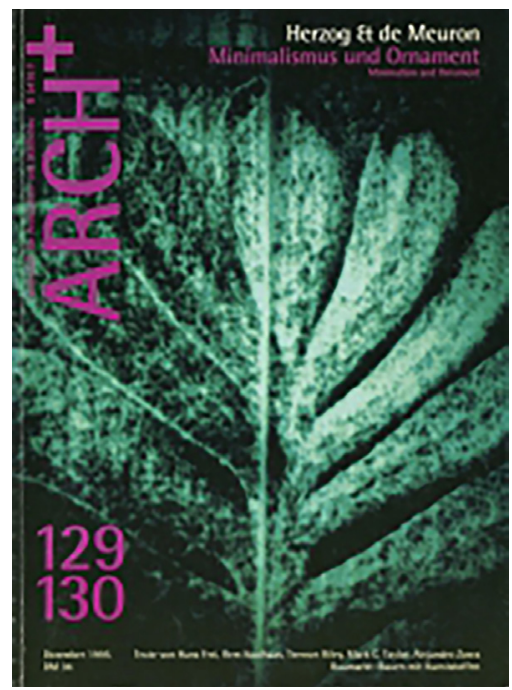

Figura 11 | Capa da $A R C H+129 / 130,1995$ : Minimalismus und Ornament. Fonte: http://www.archplus.net/ 


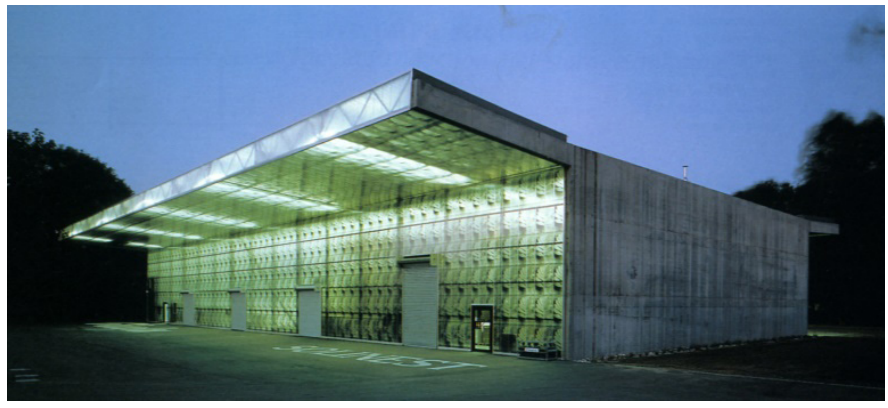

Figura 12 | Vista externa no começo de noite, Ricola-Europe (1992-1993).

Fonte: Thomas Ruff, http://metamodernarchitecture.blogspot.com 
No caso de Ricola-Europe, todas as superfícies do edifício são configuradas por padrões. A forma da construção é a de uma caixa de papelão com abas levantadas em dois lados, formando marquises em balanço que marcam os acessos. Essas fachadas e o forro das marquises são de policarbonato translúcido em que um motivo vegetal, adaptado de uma fotografia do artista alemão Karl Blossfeldt24 (1865-1932), foi impresso em escala de cinza nas placas por técnica simples de silkscreen. O efeito gerado é impressionante, pois de acordo com a luminosidade externa, o padrão é mais ou menos visível. À noite, com a iluminação interna, a repetição do motivo vegetal é ressaltada, assim como se visto de dia pelo seu interior. É como um papel de parede mais ou menos transparente cuja intensidade do padrão é variável e relativamente fora do controle humano. As outras duas fachadas são de concreto escuro, mas diferentemente de um edifício brutalista, não é a textura do concreto que se destaca. A água da chuva é direcionada do telhado

\footnotetext{
24. Karl Blossfeldt era interessado nos padrões repetitivos encontrados nas formas da natureza e ficou conhecido pelas suas fotografias em close-up de plantas e outros seres vivos. Publicou uma coleção em 1929, no livro Urformen der Kunst (a tradução literal seria "Formas de Arte Únicas", mas é traduzido para o inglês como Art Forms in Nature). Blossfeldt é particularmente importante por ter imprimido uma dimensão abstrata e geométrica para as coisas vivas, por meio de seu olhar pela câmera. De modo semeIhante, mas um pouco mais figurativo, foi o trabalho influente do compatriota alemão Ernst Haeckel (1834-1919) com a publicação em 1904 de seus principais desenhos em Kunstformen der Natur (Formas de Arte na Natureza), que discutiu o caráter ornamental, geométrico abstrato, dos padrões complexos encontrados micro-organismos e criaturas marítimos.
} 
para escorrer por essas superfícies, marcando-as pelo seu fluxo até atingir uma vala de seixos e ser devolvida ao solo. Mulhouse-Brunstatt possui um índice pluviométrico muito alto e constante o ano todo, o que garante a permanente mutabilidade das fachadas de concreto. Não só a água gera padrões verticais variados, mas a vida vegetal que passa a se conformar pela umidade adiciona mais complexidade pela superposição textural. Em um dia nublado, todas as fachadas assumem certa homogeneidade pela similaridade de efeito da parede de concreto e a verticalidade e ligeira opacidade (pelo reflexo da luz difusa) dos painéis de policarbonato.

Nesse projeto, a padronagem da superfície de policarbonato é como uma cortina, com um caráter têxtil, mas que altera não só o grau de visibilidade, mas, também, a natureza dessa visibilidade. Um paralelo interessante pode ser feito com efeito da projeção em superfícies, cada vez mais comum e acessível por meio da técnica de $3 d$ video mapping, um mapeamento tridimensional de superfícies que permite a adaptação da projeção à forma exata do edifí$\mathrm{cio}^{25}$. As estratégias ornamentais de Herzog e de Meuron

25. As projeções em edifícios têm tido naturezas e propósitos distintos, variando da criticidade de Jenny Holzer à espetacularidade diária no Castelo da Cinderella da Disney. No entanto, a técnica do $3 d$ vídeo mapping possibilita a sobreposição de outra textura temporária (e potencialmente dinâmica) sobre uma materialidade existente. Nos termos de Ruskin, seria um wall-veil, mas temporário e, de acordo com seu caráter crítico e 
para esse projeto provocam outra interpretação do caráter temporal que Ruskin pretendia para o ornamento: o padrão na natureza se desdobra no tempo, e assim deveria ser na arquitetura.

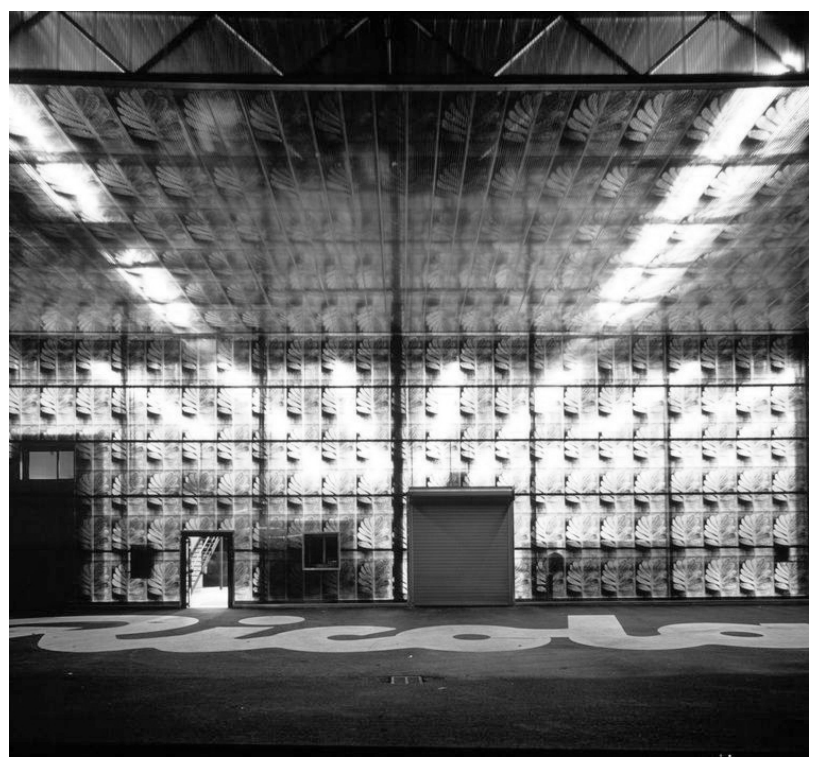

Figura 13 | Vista externa com painéis ornamentais, Ricola-Europe (1992-1993). Fonte: http://afasiaarchzine.com

capacidade empática, poderia possibilitar um alargamento ontológico a partir de sua experiência real. 


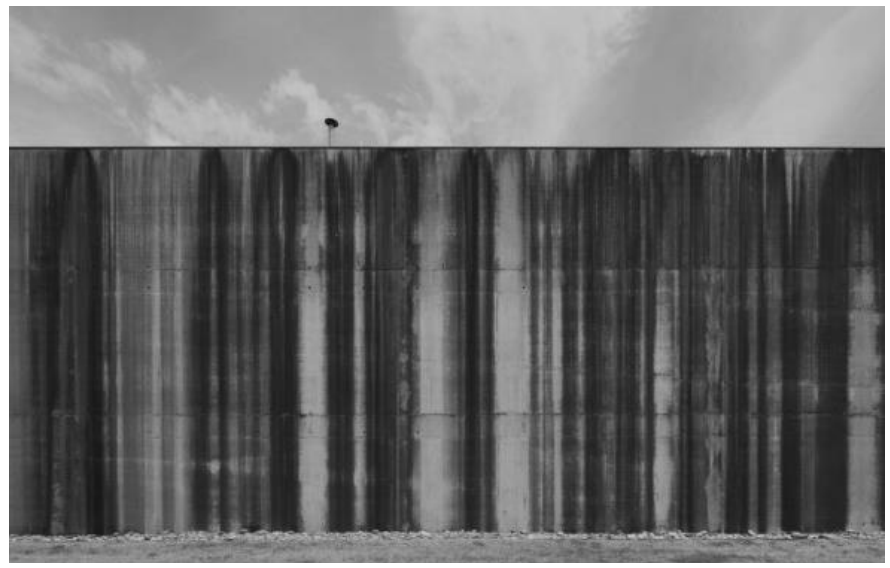

Figura 14 | Padrão aleatório gerado pela água na parede externa de concreto, RicolaEurope (1992-1993). Fonte: http://hicarquitectura.com/ 


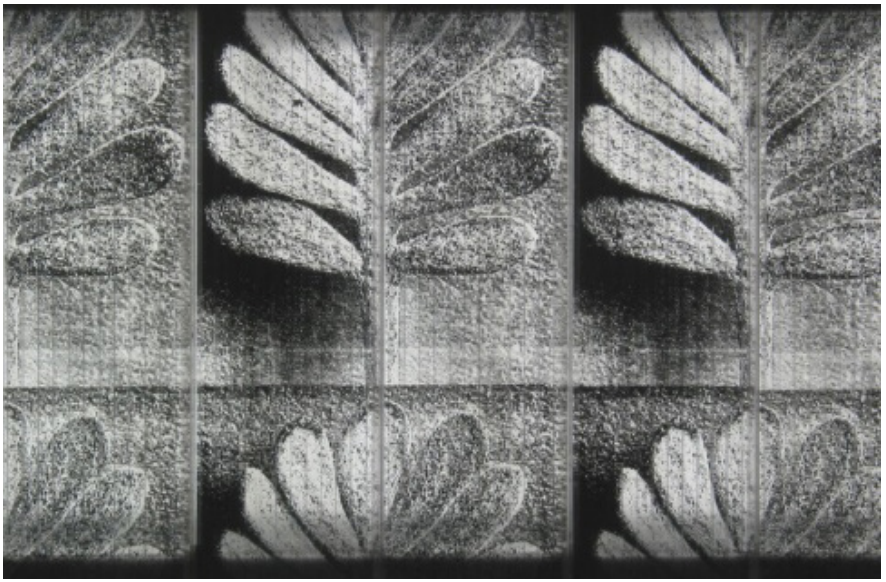

Figura 15 | Detalhe do painel de policarbonato, Ricola-Europe (1992-1993).

Fonte: Maarten Helle@ MIMOA, www.mimoa.eu 
A figura vegetal - pequenas folhas, mais ou menos compridas, irradiando de uma haste principal, com aspecto simétrico - foi escalada em um tamanho que abrange a largura de duas placas e altura de um quarto do pé-direito e organizada de forma sequencial para preencher toda a superfície. A julgar pela composição, nem Ruskin, Morris ou Jones considerariam essa estratégia um bom exemplo de ornamentação: (1) a figura utilizada no padrão é isola$\mathrm{da}$, sem continuidade com as figuras adjacentes, gerando uma estaticidade monótona e, por conseguinte, "proporciona um prazer imperfeito" ${ }^{26}$. Nesse caso, o padrão não é decorrente de uma lógica de crescimento, mas de uma repetição sem variação. (2) O padrão é tratado sem considerar a relação entre superfície e aberturas, isto é, não há um movimento de linhas que incorpore a abertura no plano opaco. As aberturas são feitas com base na necessidade de uso do espaço e na disposição das chapas de policarbonato. Como a figura ocupa duas peças, as aberturas a segmentam abruptamente. (3) O padrão é organizado em uma superfície estruturada internamente por um gradeamento metálico preto, adequado para a modulação dos painéis e da superestrutura, mas incongruente com o módulo do padrão: as linhas horizontais e verticais da estrutura irrompem na imagem e a segmentam aleatoriamente. Desse modo, 
Spuybroek não consideraria essa superfície como padrão, mas como textura, em um sentido pejorativo:

\begin{abstract}
Textura é o que eu chamaria de decoração fraca: nenhuma relação entre padrão e o objeto. Decoração fraca é simplesmente aplicada independentemente sobre uma forma e uma estrutura preexistentes. Em contraste, na decoração forte, como a de Morris, o padrão "constrói" ou "cria" o objeto, incluindo todas as suas características, como limites, cantos e aberturas. Observe que isso não significa que o ornamento literalmente antecede a forma ou a superfície, mas, ornamento é fazer abstrato, (...), ele recria a superfície geométrica, por exemplo, da parede abstratamente, a partir de regras de crescimento como bifurcação, curvatura tangencial e outros. ${ }^{27}$
\end{abstract}

No entanto, Spuybroek poderia muito bem avaliar positivamente a clara intenção de transformação da figura pictórica em uma pele abstrata pela sua escala e repetição. De uma distância, a abstração textural é percebida, tanto na parede de policarbonato como na de concreto, mas à medida que se aproxima do edifício, o que se percebe é a reprodução de uma fotografia - uma meta-reprodução - e a real materialidade dos musgos e manchas na parede de concreto. Não existe a intenção de representação pelo uso da figura, mas um hábil jogo de transdimensionalidade da imagem e do visível que exige do sujeito a formação de 
camadas perceptivas variadas. Contudo, por se tratar de uma fábrica situada em um contexto urbano desfavorável para o percurso a pé e cuja visibilidade do passeio e da rua é obstruída por linhas de árvores, a experiência fica restrita aos usuários da fábrica - o que não invalida a proposta, mas limita sua repercussão ${ }^{28}$.

Bernard Cache, em Digital Semper, de 2002, declara que o padrão, considerado por Semper como o modo ornamental de derivação têxtil, possui dois grandes potenciais: (1) o princípio da euritimia, ou modulação, que diz da capacidade de criar "sequências de intervalos espaciais exibindo configurações análogas" 29 . Cache compara a sequência de alternância, enquanto repetição rítmica de partes distintas, com o processo de parametrização digital. (2) O padrão será visto como transdimensional, podendo, pela operação de transposição (Stoffwechsel em alemão, que significa transformação material), configurar novas possibilidades formais. $\mathrm{O}$ arquiteto vislumbra que a materialidade plástica, dobrável, eurítimica do tecido, da envoltória, pode ser transposta para processos digitais de fabricação.

Um dos projetos mais impressionantes que Lars Spuybroek

28. É possível que a repercussão do edifício pela publicação em veículos midiáticos seja maior que a do edifício em si.

29. CACHE, Bernard. Projectiles. London: Architectural Association, Ebook Architecture Words 6. 2002, p.6. 
desenvolveu no NOX (em parceria com o compositor Edwin van der Heide) foi a instalação arquitetônica e musical SonO-House (2000-2004). Trata-se de um pavilhão público ${ }^{30}$ localizado no Science Park Eindhoven (Son en Breugel, Holanda), à beira de um lago, em que o movimento dos corpos no espaço é detectado por sensores e ativam certas sonoridades, e ao longo do tempo sinfonias são configuradas. O projeto materializa antecipadamente sua teoria do ornamento contemporâneo.

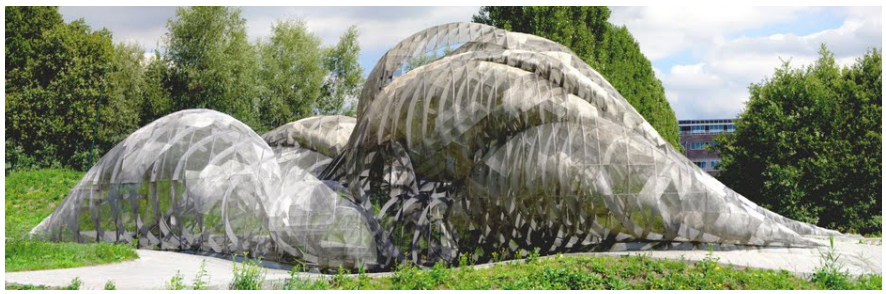

Figura 16 | Exterior da Son-O-House (2000-2004). Fonte: Wikipedia Commons. 
A forma do pavilhão pode ser comparada a um cabelo escovado e trançado, e traduz as operações de tesselação (tesselation) ${ }^{31}$ e de nervura (ribboning) ${ }^{32}$ do campo da superfície - como os papéis de parede de Morris - para o campo da massa. As massas onduladas se fundem suavemente, ora acoplando-se na massa adjacente, ora penetrando-a formando um conjunto complexo a partir da operação de tesselação. Esse processo é o de transformação da superfície em uma malha de linhas de modo a formar um padrão. No caso de Son-O-House é como se um tecido elástico fosse esticado no solo e cabos fossem entrecruzados ao longo da superfície e afixados nas bordas, criando um padrão bidimensional. Quando esse tecido fosse inflado, por exemplo, 170 protuberâncias orgânicas iriam se formar nas partes entre os cabos, deformando a superfície. A pele que gera o conjunto ondulado é constituída de tiras de tela metálica soldadas entre si e com dois tamanhos de trama, que criam um efeito textural. Assim, pela associação feita aqui, a textura

31. Spuybroek compara a tesselação ao processo de fissura de um solo argiloso quando sob condições áridas, que nesse caso gera um aspecto craquelado.

32. Termo escolhido por Spuybroek para substituir band ornament (moldura) e arabesque (arabesco). Ribbon em inglês significa "fita ou faixa de elemento têxtil", já o termo rib significa "costela" (anatomia humana) ou "nervura" (em botânica é o filamento ramificado e saliente das folhas ou ainda o filete córneo das assas dos insetos). Spuybroek (2011, p.347) explica em nota que "há uma relação profunda entre os dois [ribbon e rib]: a nervura ornamental age estruturalmente e a nervura estrutural age ornamentalmente, por ambas usarem elementos lineares flexíveis para construir entidades maiores". 
gerada pelo patchwork de telas assemelha-se ao conjunto de fios do cabelo, ao passo que a forma ondulada seria o trançado de mechas desse cabelo, isto é, sua tesselação.

Spuybroek ${ }^{33}$ explica que enquanto a "tesselação opera da superfície para a linha" e configura um ornamento mais "mineral", "a nervura opera da linha para a superfície" e tem uma qualidade mais "vegetal." As nervuras da Son-OHouse agem para construir a superfície: cada protuberância possui dois grupos de costelas que se sobrepõem em ângulo conformando uma trama com pontas abertas. Quando uma massa se funde ou penetra em outra, algumas pontas de costela se unem e criam uma estrutura única e coesa. $O$ ritmo regular de espaçamento na repetição dos elementos e a variação na curvatura e no comprimento formam um padrão complexo. O espaço é criado pelo contorno dos elementos. A forma atingiu sua configuração final física pela confluência dos processos ali impostos - a textura, a tesselação e a nervura - e o seu controle a partir de parâmetros, regras. As peças de geometria variável foram produzidas com precisão, utilizando tecnologias de fabricação digital. 


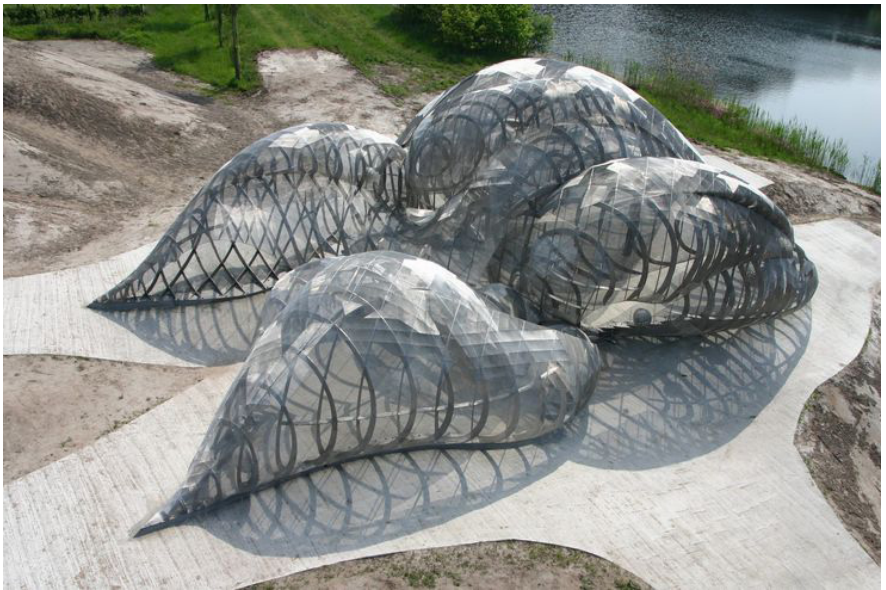

Figura 17 | Vista aérea da Son-O-House (2000-2004).

Fonte: www.nox-art-architecture.com/. 


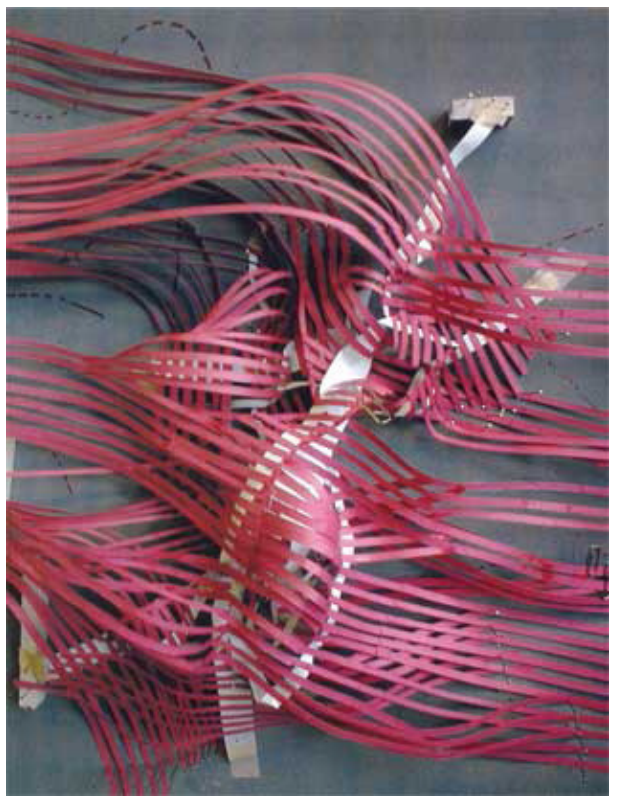

Figura 18 | Maquete de processo da Son-O-House (2000-2004). Fonte: www.nox-art-architecture.com/ 


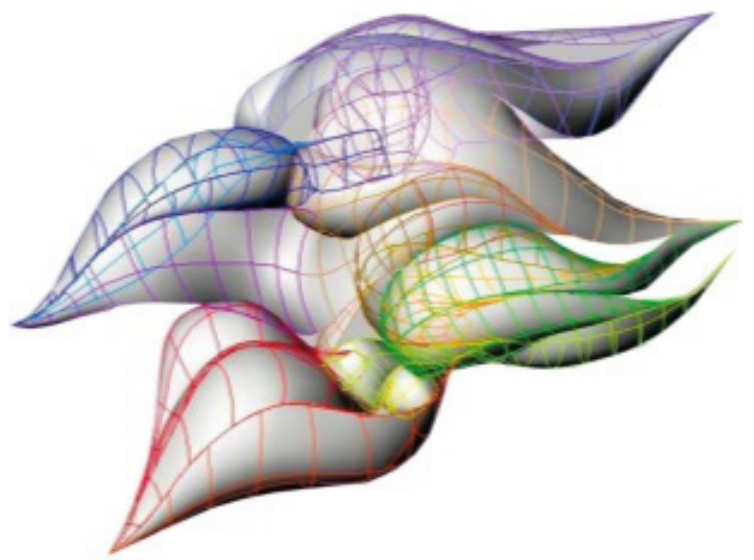

Figura 19 | Modelo digital da Son-O-House (2000-2004).

Fonte: www.nox-art-architecture.com/. 


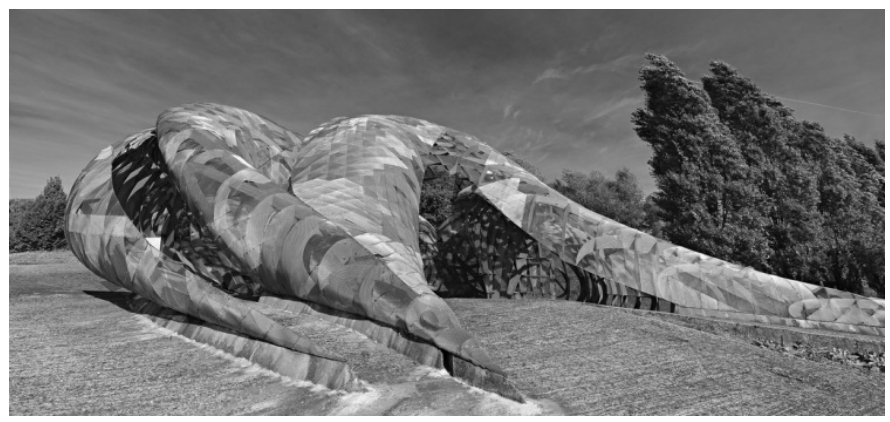

Figura 20 | Vista externa da Son-O-House (2000-2004). Fonte: Wikipedia Commons 


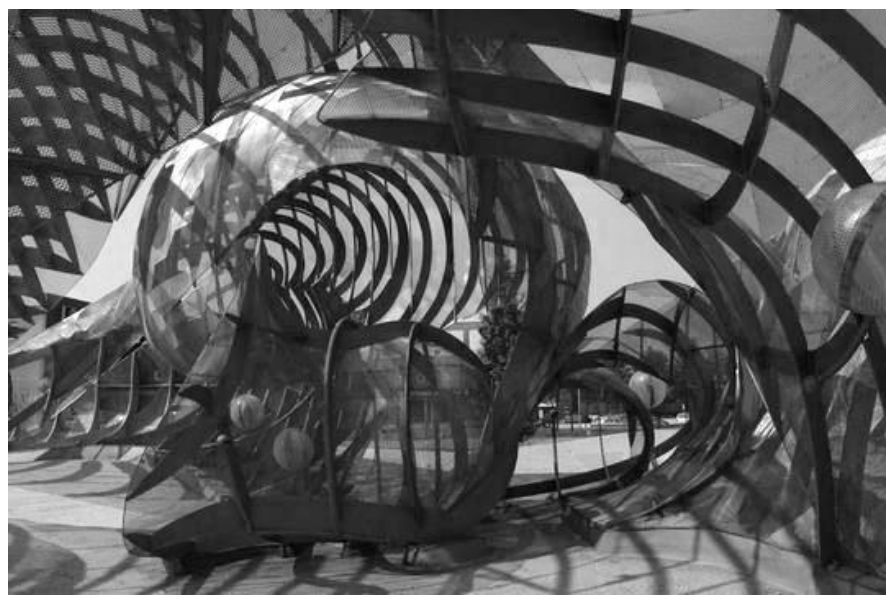

Figura 21 | Interior da Son-O-House (2000-2004).

Fonte: www.nox-art-architecture.com/ 


\section{Conclusão: a tectônica digital e a possibilidade de uma nova teoria do ornamento}

O arquiteto e teórico Neil Leach ${ }^{34}$ utiliza o termo "tectônica digital" para caracterizar as novas práticas ornamentais possibilitadas pela associação entre o uso de softwares de modelagem paramétrica, em que é possível inserir dados e parâmetros para a construção, e técnicas de fabricação digital, possibilitadas pelo sistema file-to-factory: o arquivo da forma parametrizada é enviado para a confecção em máquinas de corte (por broca e a laser), de escavação, de deposição de material (produção de camadas de barro, concreto ou outro material pastoso que ganhe rigidez estrutural), dentre outras. No entanto, a historiadora da arquitetura, Vittoria di Palma ${ }^{35}$, levanta a hipótese de que não foi apenas a facilidade tecnológica de projetar e fabricar formas complexas que simplesmente estimulou os arquitetos a rever sua relação com o ornamento. Ela sugere que deve ter havido algo mais profundo que tenha despertado esse desejo. Picon ${ }^{36}$ relaciona a presença do ornamento na contemporaneidade com a evolução da relação que os arquitetos passaram a ter com o digital.

34. LEACH, Neil (ed.); TURNBULL, David (ed.); WILLIAMS, Chris (ed.). DigitalTectonics. London: Wiley Academy, 2004. 152p.

35. PALMA, Vittoria di. A natural history of ornament. In: PAYNE, Alina (ed.); NECIPOGLU, Gulru (ed.) et al. Histories of Ornament: From Global to Local. Princeton, New Jersey: Princeton University Press, 2016. 453p.

36. PICON, 2013. 
O desejo de entender forma em termos de formação é uma das razões que a atenção que os arquitetos digitais dão aos desdobramentos científicos recentes, por exemplo na teoria dos sistemas dinâmicos ou na genética que imprime uma ênfase na propriedade de emergência [emergence] concebida como uma capacidade de auto-organização que opera por toda a natureza. ${ }^{37}$

Assim como na "Arquitetura Viva" de Ruskin"38, as qualidades de variação (variation) e mutabilidade (changefulness) são propriedades fundamentais ao ornamento contemporâneo proposto por Spuybroek ${ }^{39}$. Em termos da cultura digital, essas qualidades corresponderiam a um comportamento paramétrico. Se a parametrização de processos naturais complexos passa a ser o modo operacional do ornamento arquitetural contemporâneo - o paradigma biológico -, a fabricação digital passa a ser sua possibilidade construtiva. Reconhecida essa condição ornamental para as novas arquiteturas, faz-se necessária sua avaliação crítica, não apenas para ver seus potenciais e limitações, mas construir uma agenda que teorize seus fundamentos, delineie seus interesses e discuta suas implicações. 


\section{Referências}

BEESLEY, Philip; BONNEMAISON, Sarah. On Growth and Form: Organic Architecture and Beyond. Dalhousie University: Tuns Press and Riverside Architectural Press, 2008.

BLOOMER, Kent. The Nature of Ornament: Rhythm and Metamorphosis in Architecture. New York: W. W. Norton \& Company, 2000. 240p.

CACHE, Bernard. Earth Moves: The Fursnishing of Territories. Writing Architecture Series. Cambridge, Massachusetts: MIT Press, 1995. $175 p$.

CACHE, Bernard. Projectiles. London: Architectural Association, Ebook Architecture Words 6.

COLLETTI, Marjan (ed.). Exuberance: New Virtuosity in Contemporary Architecture. Architectural Design Magazine, London, v. 80, n.2, march/april 2010.

DELEUZE, Gilles; Félix Guattari. AThousand Plateaus: capitalism and schizophrenia. Minneapolis: University of Minneapolis Press, 1987. Tradução do francês: Brian Massumi. 612p.

DELEUZE, Gilles. Francis Bacon: a lógica da sensação. Rio de Janeiro: Jorge Zahar Ed., 2007. 183p. Tradução de Roberto Machado [at al].

A Dobra: Leibniz e o Barroco. Campinas: Papirus, 2011. 6. Ed. 240p. Tradução de Luiz Orlandi.

GOMBRICH, E. H. O sentido de ordem: um estudo sobre a psicologia da arte decorativa. Porto Alegre: Bookman Editora, 2012. 411p. Tradução: Daniela Pinheiro Machado Kern.

HESS, Alan; WEINTRAUB, Alan. Organic Architecture: The Other Modernism. Salt Lake City: Gibbs Smith, 2006. 276p.

JONES, Owen. A gramática do ornamento: ilustrado com exemplos de diversos estilos de ornamento. São Paulo: Editora SENAC, 2010. $504 p$.

LEACH, Neil (ed.); TURNBULL, David (ed.); WILLIAMS, Chris (ed.). Digital Tectonics. London: Wiley Academy, 2004. 152p. 
LEACH, Neil. Digital Morphogenesis. In PUGLISI, Luigi Prestinenza. Theoretical Meltdown. AD - Architectural Design, v. 71, n.1, 2009. p.33-37.

LEVIT, Robert. Contemporary Ornament: The Return of the Symbolic Repressed. Harvard Design Magazine, Spring/Summer 2008, n. 28. 2008. p.1-8.

LOOS, Adolf. Ornamento e crime. Lisboa: Cotovia, 2004. 279 p.

LYNN, Greg. Folding in Architecture. London: Wiley, Architectural Design Magazine, 1993.

The Structure of Ornament. Conversation with Neil Leach. In: $\mathrm{LEACH}$, Neal (org.) et al. Digital Tectonics. Bath: University of Bath, 2002. p.63-68.

Folding in Architecture. London: Wiley, Architectural Design Magazine, 2004.

MANDELBROT, Benoit. The fractal geometry of nature. New York: W. H. Freeman and company, 1983.

MOUSSAVI, Farshid (ed.); KUBO, Michael (ed.). The function of ornament. Barcelona: Actar, 2008. s/p.

PAIM, Gilberto. A Beleza sob Suspeita: o ornamento em Ruskin, Lloyd Wright, Loos, Le Corbusier e outros. Rio de Janeiro: Jorge Zahar Editor, 2000. 147p.

PALMA, Vittoria di. A natural history of ornament. In: PAYNE, Alina (ed.); NECIPOGLU, Gulru (ed.) et al. Histories of Ornament: From Global to Local. Princeton, New Jersey: Princeton University Press, 2016. 453p.

PAYNE, Alina. L'ornement architectural: du langage classique des temps modernes à l'aube du xxe siècle. Perspective [En ligne], 1 | 2010, mis en ligne le 14 août 2013. Disponível em: URL : http://perspective.revues.org/1220

PAYNE, Alina (ed.); NECIPOGLU, Gulru (ed.) et al. Histories of Ornament: From Global to Local. Princeton, New Jersey: Princeton University Press, 2016. 453p.

PICON, Antoine. Digital Culture in Architecture: an introduction for the design professions. Basel: Birkhauser, 2010. 224p. 
Ornament: The politics of Architecture and Subjectivity.

Chichester: John Wiley \& Sons, 2013. 168p.

RIEGL, Alois. Problems of style: foundations for a history of ornament. Princeton, New Jersey: Princeton University Press, 1992. 406p. Tradução para o ingles de Evelyn Kain.

RUSKIN, John. Modern Painters: Part IV. New York: John Wiley, 1863. $421 \mathrm{p}$. $222 p$.

The Seven Lamps of Architecture. New York: Dover, 1989.

Selections From the Works of John Ruskin. Cambridge, Massachusetts: The Riverside Press, 2012. 286p. Kindle Edition.

SEMPER, Gottfried. The Four Elements of Architecture and other writings. Cambridge, UK: Cambridge University Press, 2010. 314p. Tradução de Harry F. Mallgrave e Wolfgang Herrmann.

SPUYBROEK, Lars. The Sympathy ofThings: Ruskin and the Ecology of Design. Rotterdam: V2_Publishing, 2011. 400p.

WORRINGER, Wilhelm. Form Problems of the Gothic. New York: G. E. Stechert \& Co., 1920. Edição: Authorized American Edition. 146p.

Abstraction and Empathy: A Contribution to the Psychology of Style. Chicago: Ivan R. Dee, 1997. 144p. 